\title{
Biosynthesis of Ag nanoparticles using Salicornia bigelovii and its antibacterial activity
}

\author{
Mehrdad Khatami ${ }^{1,2}$, Fatemeh Golshan Noor ${ }^{3}$, Saeed Ahmadi ${ }^{3}$, Mohammadreza Aflatoonian ${ }^{4}$
}

${ }^{1}$ PhD., Biotechnologist, Associate Professor, Nanobioelectrochemistry Research Center, Bam University of Medical Sciences, Bam, Iran

${ }^{2} \mathrm{PhD}$., Biotechnologist, Associate Professor, Leishmaniasis Research Center, School of Medicine, Kerman University of Medical Sciences, Kerman, Iran

${ }^{3}$ M.Sc., Biotechnologist, Ala Ava Gene Biotechnology Company, Tehran, Iran

${ }^{4} \mathrm{Ph} . D$. of Health, Associate Professor, Research Center of Tropical and Infectious Diseases, Kerman University of Medical Sciences, Kerman, Iran

\section{Type of article: Original}

\begin{abstract}
Background and aim: In recent years, the field of nanotechnology has become the most active area of research in modern material science. While many chemical- as well as physical methods are also used, green synthesis of nanoparticles is becoming the most evolved method of synthesis. In this study, we synthesized silver nanoparticles from the seed extract of Salicornia bigelovii.

Methods: This experimental study was conducted from December 2017 to January 2018 in Kerman University of Medical Sciences, Kerman, Iran. The effects of two concentrations ( $1 \mathrm{~m} \mathrm{M}$ and $4 \mathrm{mM})$ on the synthesis of nanoparticles were studied. Characterizations were done using different methods including ultraviolet (UV) visible spectroscopy, transmission electron microscopy (TEM), X-ray diffraction (XRD), and Fourier transform infrared spectroscopy (FTIR). Antibacterial activity of Ag nanoparticles against Staphylococcus aureus and Escherichia coli was studied using microdilution method. The data were analyzed using Probit test in SPSS (Version 20, USA).

Results: Formation of the AgNPs was confirmed by surface plasmon spectra using UV-Vis spectrophotometer and absorbance peaks at $434 \mathrm{~nm}$. The FTIR spectra showed the possible role of the functional group like carbonyl groups in reduction of silver ions to silver nanoparticles. The XRD analysis showed that the synthesized silver nanoparticles are of face-centered cubic structure. The TEM showed the formation of silver nanoparticles ranging in diameter from 1 to $50 \mathrm{~nm}$. The minimal inhibitory concentration and minimal bactericidal concentration of AgNPs were determined for both S. aureus and E. coli 6.25 and $12.5 \mu \mathrm{g} / \mathrm{mL}$, respectively.

Conclusion: An environmentally friendly approach is more affordable than chemical methods. Physicochemical approaches can be harmful to the environment and to human health. Thus, the green synthesis methods are simple, less expensive, and can cut consumption of energy; they can be used for synthesis of fixed nanoparticles with preferred shape and size, without the use of toxic chemical agents.
\end{abstract}

Keywords: X-Ray Absorption Spectroscopy, Biosynthesis, Silver, Nanoparticles

\section{Introduction}

The biosynthesis of nanostructures is a green and environmentally friendly method. Gold, platinum, zirconium, cadmium, titanium oxide, zinc oxide, iron oxide, etc. are nanoparticles produced in this way. These particles are practically used in medicine, cosmetics, pharmaceutical and biochemical sensors (1-6). The synthesis of materials at the Nanoscale (1 to $100 \mathrm{~nm}$ ) has attracted the attention of many researchers due to the unique physicochemical

\section{Corresponding author:}

Associate Professor Dr. Mohammadreza Aflatoonian, Research Center of Tropical and Infectious Diseases, Kerman University of Medical Sciences, Kerman, Iran.

Tel: +98.9133982084, Fax:+98.34344219074, Email: mraflatoonian@gmail.com

Received: November 10, 2017, Accepted: February 06, 2018, Published: April 2018

iThenticate screening: January 25, 2018, English editing: February 24, 2018, Quality control: March 12, 2018

This article has been reviewed / commented by five experts

(C) 2018 The Authors. This is an open access article under the terms of the Creative Commons Attribution-NonCommercialNoDerivs License, which permits use and distribution in any medium, provided the original work is properly cited, the use is non-commercial and no modifications or adaptations are made. 
properties (7-10). Materials at the Nanoscale, which are called nanostructured, take many forms. From a variety of nanostructures, nanoparticles are widely produced and used in different sciences (11-13). Silver nanoparticles are the most used nanoparticles. Various chemical and physical methods have been used for the synthesis of nanoparticles. But these methods are often ineffective and have harmful effects on the environment $(14,15)$. Another method recently used for the synthesis of nanostructures is the use of biological resources to produce nanostructures called biosynthesis (16-18). Today, the synthesis of nanoparticles has been carried out with bacteria, fungi, plants and even insects (19-21). In comparison with most physical and chemical methods, this approach is cost effective, safe and environmentally friendly, and has shown a high performance $(22,23)$. Nanoparticles (NPs) have been of great concern due to their electrical, optical, magnetic, engineering and energy properties (24-31). The bioreduction properties of some bioresources such as Phoenix dactylifera, Sinapis arvensis, Banana (32), Fusarium solani (33), olive (34), Brassica oleracea (35), Streptomyces microflavus, Streptomyces somaliensis, carob (36), cobweb (37) and worm (38) have been studied in the synthesis of silver nanoparticles. In this study, we used the seed extract of Salicornia bigelovii (Figure 1) for synthesis of silver nanoparticles. As an important useful plant in food industry, Salicornia bigelovii is halophyte, and is used for desertification. Salicornia bigelovii is from the Chenopodiaceae family whose seeds contain $18 \%$ protein and $24 \%$ oil of which $70 \%$ are linoleic acid (omega-6). The following information about the analysis and the results of UV-visible spectroscopy, XRD, TEM, FTIR of synthesized AgNPs is described.
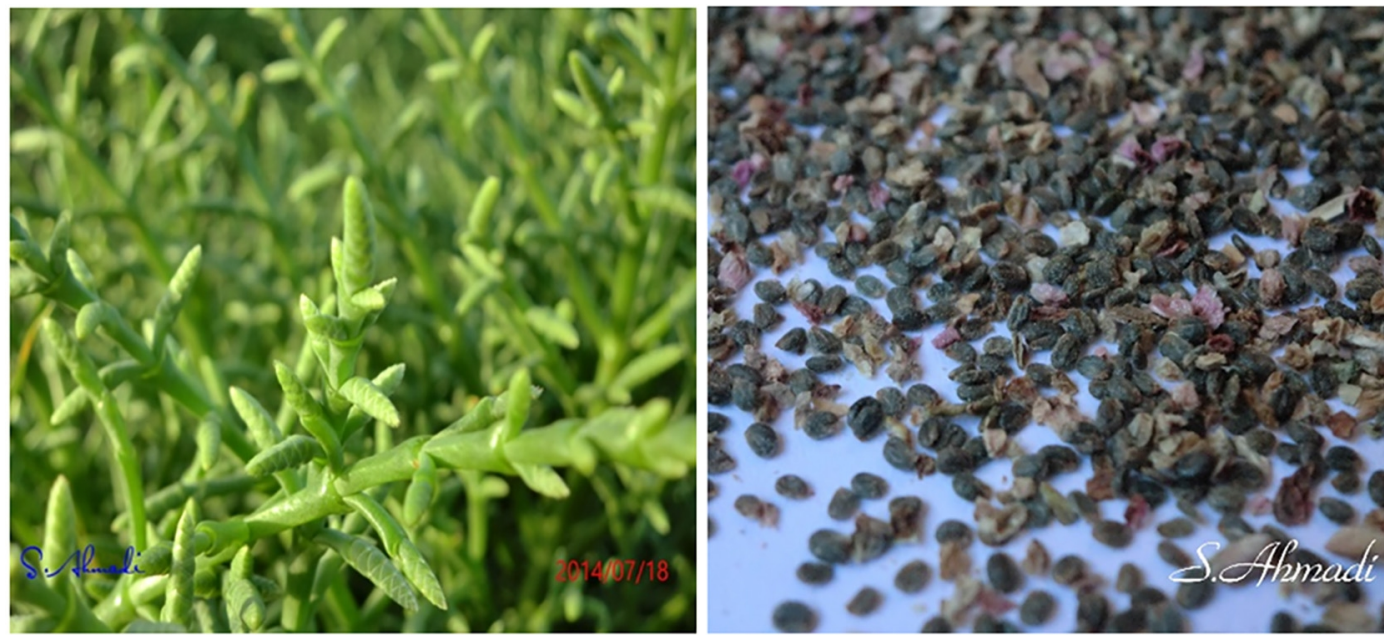

Figure 1. The plants and seeds of Salicornia bigelovii.

\section{Material and Methods}

\subsection{Biosynthesis}

This experimental study was conducted from December 2017 to January 2018 in Kerman University of Medical Sciences, Kerman, Iran. Seeds of Salicornia bigelovii. Torr were obtained from BO Da Yi investment and development Co, Shanghai, China. First, they were washed with water for cleaning the dust and then disinfected with $70 \%$ alcohol for approximately 2 minutes. They were then washed 3 times for approximately 2 minutes with deionized water. In the next step, we added 5 grams of the seeds to $250 \mathrm{ml}$ Erlenmeyer flasks, containing $100 \mathrm{ml}$ of deionized water boiling for 15 minutes, and then brought to room temperature. Finally, the seeds were poured out and the remaining extract was filtered using paper Whatman No. 1. The extract was used as the reduction and stabilization for the synthesis of silver nanoparticles. The extracts were stored at $4{ }^{\circ} \mathrm{C}$ in the dark. The Silver nitrate $\left(\mathrm{AgNO}_{3}\right)$ used to synthesize silver nanoparticles were obtained from Merck, Germany. For this synthesis, silver nanoparticles were used for final concentration $(1$ and $4 \mathrm{mM}$ ) from silver nitrate solution. It was done so that $15 \mathrm{ml}$ of the extract was added to $30 \mathrm{ml}$ from 1 and $4 \mathrm{mM}$ primary stock separately. $\mathrm{AgNO}_{3}$ was not added to the control sample. Finally, the samples were kept in the dark at $28^{\circ} \mathrm{C}$.

\subsection{Characterization of AgNPs}

To prove the production of silver nanoparticles, we used Absorption spectra UV-visible (Scan Drop Company Analytik Jena, Germany). The formation and quality of the compounds were checked by X-ray diffraction (XRD) spectrum (PANalitical, X PERTPRO, Holland) with CuK $\alpha$ radiation $\lambda=1.5405 \AA$ (Bragg angles: $10^{\circ} \leq 2 \theta \leq 70^{\circ}$ ). FTIR (Bruker Tensor 27 of Germany) of the samples was measured. After $24 \mathrm{~h}$ of reaction with the S. bigelovii seed 
extract, the silver nanoparticles were centrifuged at $10,000 \mathrm{rpm}$ for 10 minutes, and the dry powder of the nanoparticle was obtained and used for analysis. The size and morphology of the synthesized nanoparticles in the seed extract were examined using Transmission Electron Microscopy (TEM), the product of Carl ZIESS, Germany. The sample was suspended in distilled water, dispersed ultrasonically (5 mins) to separate individual particles, and one or two drops of the suspension was deposited on to hydrocarbon coated copper grids and dried under infrared lamp

\subsection{Bioassay antibacterial activity of AgNPs}

Staphylococcus aureus and Escherichia coli were obtained from the Pasteur Institute, Tehran, Iran. The standard microdiffusion method using 96-well sterile microtiter plate was used to study the minimal inhibitory concentration (MIC) and minimal bactericidal concentration (MBC). The bacterial suspension (1 day-old) was inoculated in the wells containing different concentrations of Ag nanoparticles. After $24 \mathrm{~h}$ of incubation of the samples at $37^{\circ} \mathrm{C}$, optical densities at $600 \mathrm{~nm}$ was recorded (BioTek's PowerWave XS2, USA). MIC is the lowest concentration of the nanoparticles to inhibit the growth of bacterial cells. MBC was the concentration at nanoparticles which killed 99\% of bacterial cells. The data were analyzed using Probit test in SPSS (Version 20, USA) (39).

\section{Results}

\subsection{UV-visible}

During the biosynthesis using the extract, the color of the reaction medium changed rapidly to dark brown (Figure 2B) due to Surface Plasmon Resonance (SPR). Synthesis of AgNPs from two concentrations (1 and 4mM) of AgNO3 was confirmed by using UV-vis spectroscopy. The absorption spectra of AgNPs solution showed a Surface Plasmon Resonance with a peak at $434 \mathrm{~nm}$. (Figure 2-B). The characterization results are for AgNPs which were obtained with $4 \mathrm{mM} \mathrm{AgNO}_{3}$.
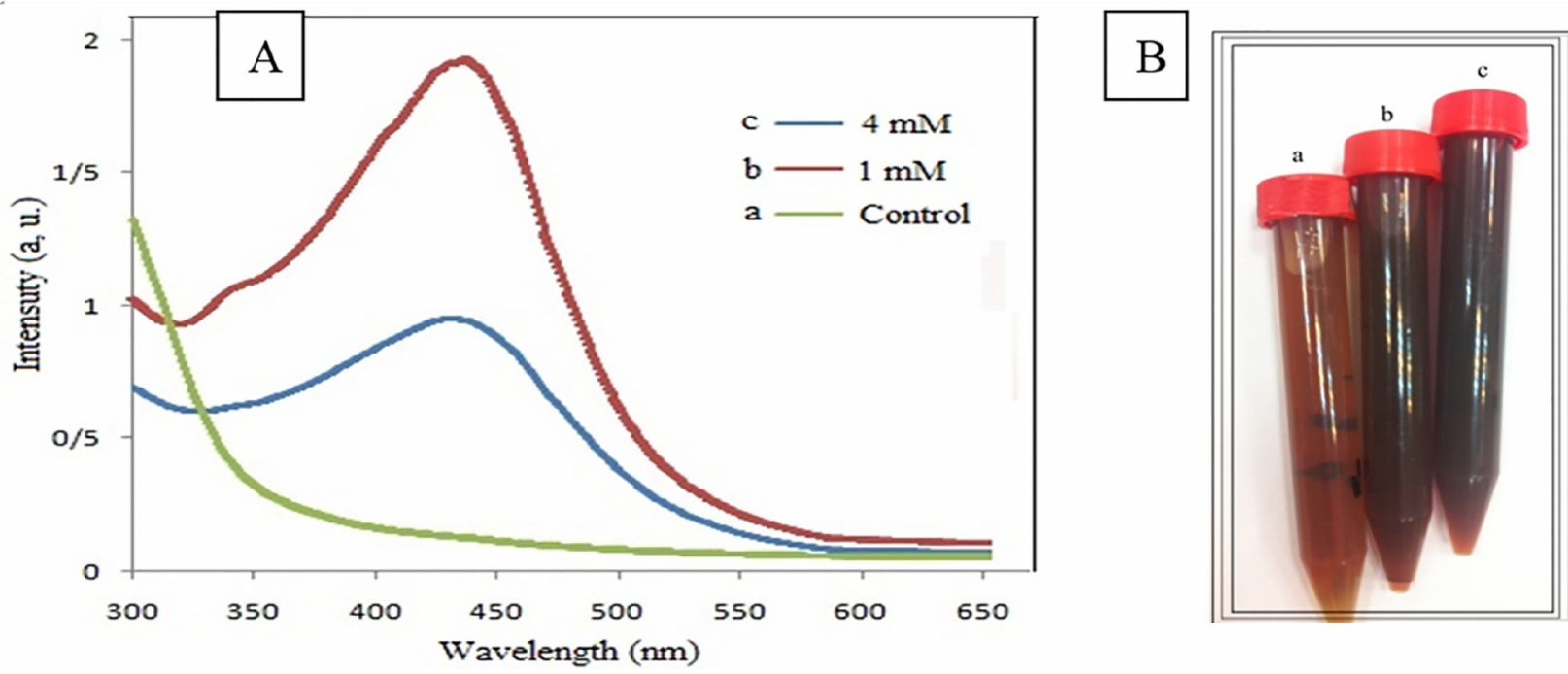

Figure 2. (A): Color change of the Salicornia bigelovii seed extract rapidly from light brown to dark brown after treatment with different concentrations of: 1(b) and 4 (c) mM silver nitrate; (B): UV-vis absorption of silver nanoparticles at $28^{\circ} \mathrm{C}$ synthesized using different concentrations of: 0 (a), 1 (b) and 4 (c) $\mathrm{mM}$ silver nitrate.

\section{2. $X R D$}

Four main characteristic diffraction peaks for Ag which are denoted by $(*)$ were observed at $38.176,44.11,64.543$, and 77.311, which correspond to the (111), (200), (220), and (311) crystallographic planes of face centered cubic (FCC) Ag crystals, respectively (Figure 3).

\subsection{TEM}

TEM analysis was used to reveal the formation and the corresponding morphology of the silver nanoparticles. The TEM images are shown in Figure 4. The TEM image shows AgNPs ranging in diameter from 1 to $50 \mathrm{~nm}$. 


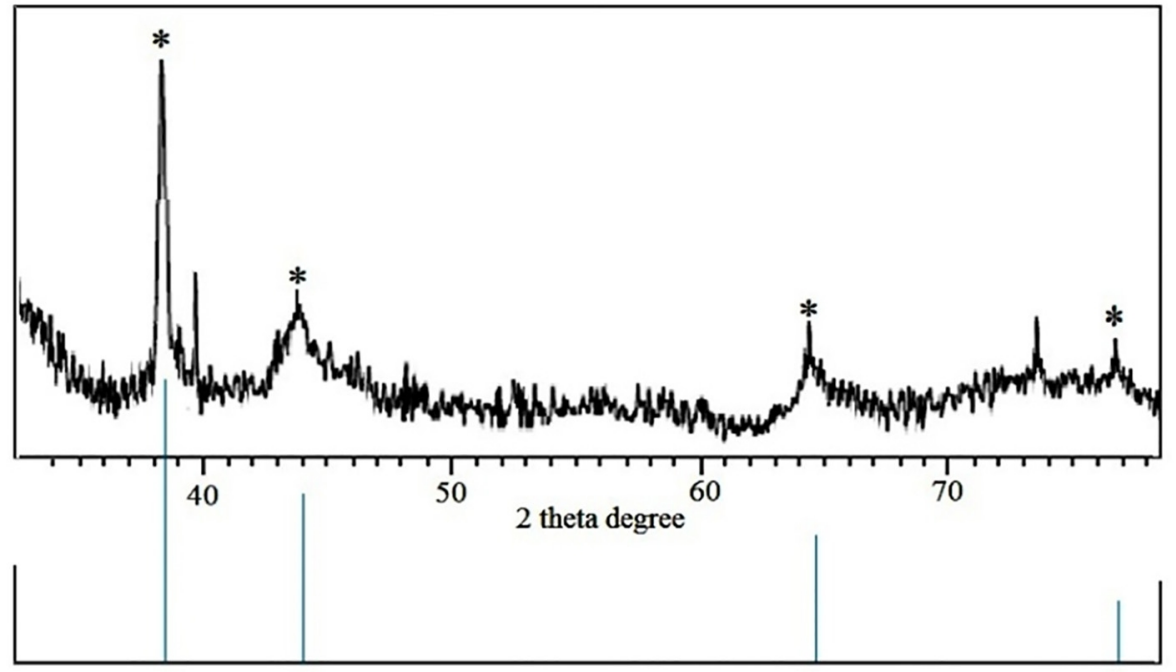

Figure 3. XRD pattern of silver nanoparticles synthesized using Salicornia bigelovii
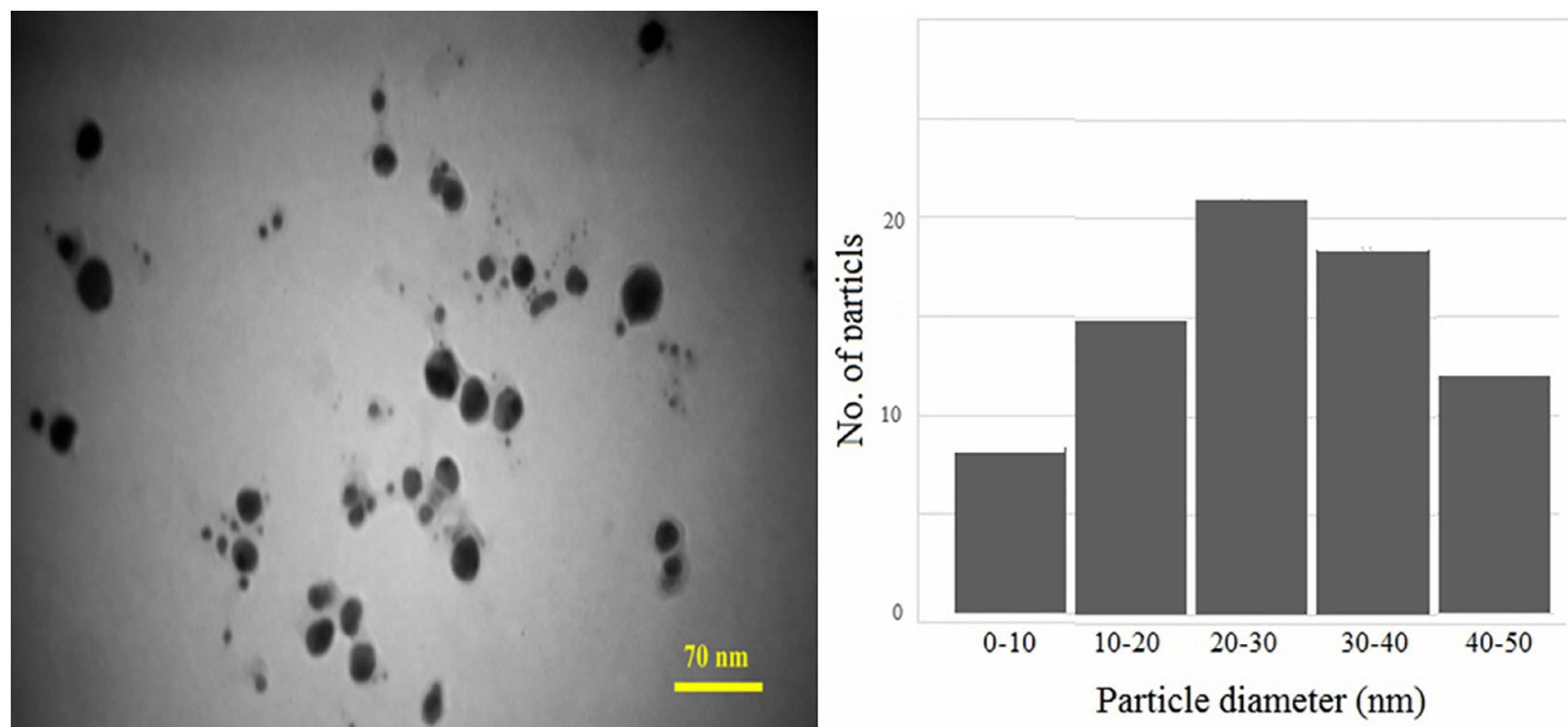

Figure 4. TEM images of silver nanoparticles synthesized at $30^{\circ} \mathrm{C}$ and $5 \mathrm{~mL}$ extract Salicornia bigelovii and plot size and frequency of the nanoparticles and histogram of particles size distribution.

\subsection{FTIR}

Vibration characteristics of chemical functional groups in a sample are identified using infrared spectroscopy. When infrared light interacts with matter, its chemical bonds will contract, stretch, and bend. Regardless of the structure of the rest of the molecule, a chemical functional group tends to adsorb infrared radiation in a specific wavenumber range, as a result. Hence, the correlation of the band wave number position with chemical structure is used for recognizing a functional group in a nanoparticle associated molecule in a sample. A number of strong bands were in FTIR spectra (Figure 5). It has been reported that proteins can provide a good protective environment for metal hydrosol during their growth processes (Mitra and Das 2008). The band at $1426 \mathrm{~cm}-1$ is assigned to the methylene scissoring vibrations from the proteins. It is well known that proteins can bind to silver nanoparticle through either free amine groups or cysteine residues in the proteins (Gole et al. 2001) and therefore, stabilization of silver nanoparticles by the surface bound proteins is possible in the present green synthesis. The extract samples show strong absorption bands at 3750, 3443, 2927, 2367, 1636 and $1426 \mathrm{~cm}-1$. The bands at $1636 \mathrm{~cm}-1$ are characteristic of amide I (Caruso et al. 1998). The amide band I is assigned to the stretch mode of the carbonyl group coupled to the amide linkage. The FTIR results indicate the presence of proteins and other biomolecules in the seed extract, and these biomolecules might participate in the formation of Ag nanoparticles. The sensitivity of S. aureus and E. coli to 
the AgNPs produced by ecofriendly method was tested by microdiffusion assay. The MIC and MBC of AgNPs were determined for both S. aureus and E. coli 6.25 and $12.5 \mu \mathrm{g} / \mathrm{mL}$, respectively. Antibacterial tests showed a significant activity against the tested bacteria. The AgNPs showed a significant antibacterial effect against the tested bacteria, while the extract (Control negative) did not show antibacterial effect.
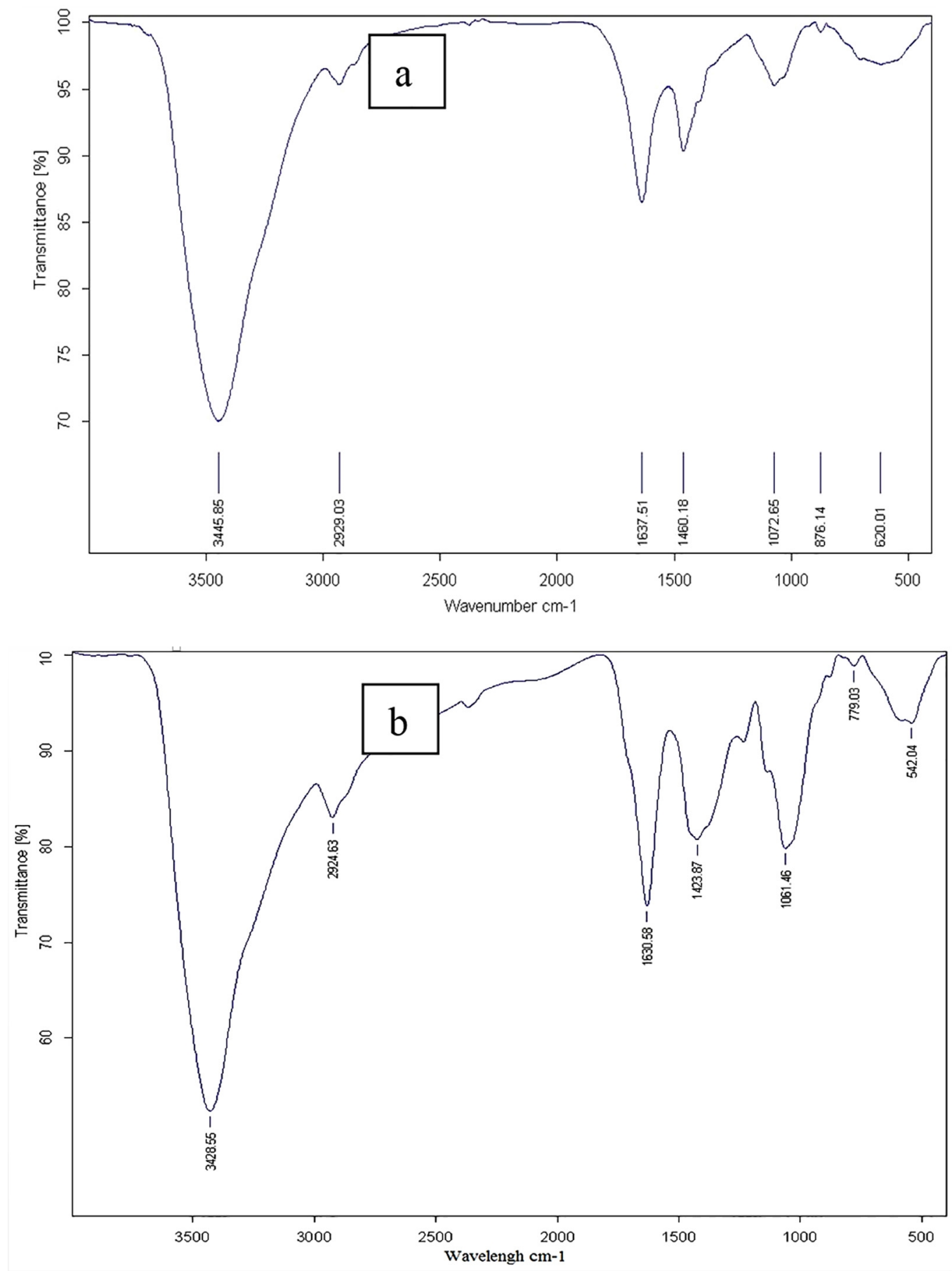

Figure 5. FTIR spectra a): before and b): after synthesis nanoparticles.

\section{Discussion}

Silver nanoparticles ( 1 to 50 ) nm were synthesized using a cheap, simple and environmental method. Antimicrobial effects of silver nanoparticles compared with Salicornia extract alone broth microdilution method were investigated. The MIC and MBC of AgNPs were determined for both S. aureus and E. coli 6.25 and $12.5 \mu \mathrm{g} / \mathrm{mL}$, respectively. 
Mirza Jani et al. studied the effects of silver nanoparticles on Staphylococcus aureus PTCC1431 and reported that minimum inhibitory concentration was $4 \mu \mathrm{g} / \mathrm{ml}$ (40). Wadi et al. studied the effect of silver nanoparticles on Staphylococcus aureus, Staphylococcus aureus which are resistant to methicillin (MSRA) and Candida glabrata and the minimum inhibitory concentration was reported $1.95,1.95$ and $15.63 \mu \mathrm{g} / \mathrm{ml}$, respectively (41). Khamenei et al.. declared that minimum growth inhibitory concentration (MIC) and minimum concentration which destroyed more than 99 percent of Staphylococcus epidermidis bacterial cells were 8 and $32 \mu \mathrm{g} / \mathrm{ml}$, respectively ((42). While in our research, minimum inhibitory concentration of silver nanoparticles was determined at $6.25 \mu \mathrm{g} / \mathrm{ml}$.

\section{Conclusions}

Silver nanoparticles with a size range of 1 to $50 \mathrm{~nm}$ were synthesized using Salicornia extracts without using any foreign chemical composition. Synthesis using the natural source is very inexpensive, simple and environmentally friendly. Antimicrobial effects of silver nanoparticles compared with Salicornia extract alone broth microdilution method were investigated. A green approach would be less expensive than chemical methods. Physicochemical approaches could be hazardous to the environment and to human health. The green synthesis approaches are simple, more affordable, and reduce energy consumption, which can be used for synthesis of fixed nanoparticles with preferred shape and size, without the use of toxic chemical agents.

\section{Acknowledgments:}

The authors acknowledge Kerman University of Medical Sciences, Bam University of Medical Sciences and Shiraz University of Medical Sciences (15644) for supporting this research.

\section{Conflict of Interest:}

There is no conflict of interest to be declared.

\section{Authors' contributions:}

All authors contributed to this project and article equally. All authors read and approved the final manuscript.

\section{References:}

1) Khatami M, Alijani H, Sharifi I. Biosynthesis of bimetallic and core shell nanoparticles: their biomedical applications: A review. IET Nanobio. 2018; 1-19. doi: 10.1049/iet-nbt.2017.0308.

2) Khatami M, Alijani H, Nejad M, Varma R. Core@shell nanoparticles: Greener synthesis using natural plant products. Applied Sci. 2018; 8(3), 411. doi: 10.3390/app8030411.

3) Bansod SD, Bawaskar MS, Gade AK, Rai MK. Development of shampoo, soap and ointment formulated by green synthesised silver nanoparticles functionalised with antimicrobial plants oils in veterinary dermatology: treatment and prevention strategies. IET Nanobiotechnol. 2015; 9(4): 165-71. doi: 10.1049/iet-nbt.2014.0042. PMID: 26224344.

4) Chaloupka K, Malam Y, Seifalian AM. Nanosilver as a new generation of nanoproduct in biomedical applications. Trends Biotechnol. 2010; 28(11): 580-8. doi: 10.1016/j.tibtech.2010.07. PMID: 20724010.

5) Sintubin L, Verstraete W, Boon N. Biologically produced nanosilver: current state and future perspectives. Biotechnol Bioeng. 2012; 109(10): 2422-36. doi: 10.1002/bit.24570. PMID: 22674445.

6) Choi $\mathrm{O}, \mathrm{Hu} \mathrm{Z}$. Size dependent and reactive oxygen species related nanosilver toxicity to nitrifying bacteria. Environ Sci Technol. 2008; 42(12): 4583-8. PMID: 18605590.

7) Darroudi M, Sarani M, Kazemi Oskuee R, Khorsand Zak A, Amiri MS. Nanoceria: Gum mediated synthesis and in vitro viability assay. Ceramics International. 2014; 40(2): 2863-8. doi: 10.1016/j.ceramint.2013.10.026.

8) Rahi A, Sattarahmady N, Helis H. Zepto-molar electrochemical detection of Brucella genome based on gold nanoribbons covered by gold nanoblooms. Sci Rep. 2015; 5: 18060. doi: 10.1038/srep18060. PMID: 26657828, PMCID: PMC4677304.

9) Negahdary M, Heli H. Applications of Nanoflowers in Biomedicine. Recent Pat Nanotechnol. 2017. doi: 10.2174/1872210511666170911153428. PMID: 28901846.

10) Moradi M, Sattarahmady N, Rahi A, Hatam GR, Sorkhabadi SMR, Heli H. A label-free, PCR-free and signal-on electrochemical DNA biosensor for Leishmania major based on gold nanoleaves. Talanta. 2016; 161: 48-53. doi: 10.1016/j.talanta.2016.08.030. PMID: 27769435.

11) Karthik K, Dhanuskodi S, Gobinath C, Prabukumar S, Sivaramakrishnan S. Nanostructured CdO-NiO composite for multifunctional applications. Journal of Physics and Chemistry of Solids. 2018; 112: 106-18. doi: 10.1016/j.jpcs.2017.09.016. 
12) Karthik K, Dhanuskodi S, Prabu Kumar S, Gobinath C, Sivaramakrishnan S. Microwave assisted green synthesis of $\mathrm{MgO}$ nanorods and their antibacterial and anti-breast cancer activities, Materials Letters. 2017; 206: 217-20. doi: 10.1016/j.matlet.2017.07.004.

13) Karthik K, Dhanuskodi S, Gobinath C, Prabukumar S, Sivaramakrishnan S. Andrographis paniculata extract mediated green synthesis of $\mathrm{CdO}$ nanoparticles and its electrochemical and antibacterial studies. Journal of Materials Science: Materials in Electronics. 2017; 28: 7991-8001. doi: 10.1007/s10854-0176503-8.

14) Jamdagni P, Khatri P, Rana JS. Green synthesis of zinc oxide nanoparticles using flower extract of Nyctanthes arbor-tristis and their antifungal activity. Journal of King Saud University-Science. 2016. doi: 10.1016/j.jksus.2016.10.002.

15) Jamdagni P, Khatri P, Rana JS. Nanoparticles based DNA conjugates for detection of pathogenic microorganisms. International Nano Letters. 2016; 6: 139-146. doi: 10.1007/s40089-015-0177-0.

16) Gopinath K, Karthika V, Sundaravadivelan C, Gowri S, Arumugam A. Mycogenesis of cerium oxide nanoparticles using Aspergillus niger culture filtrate and their applications for antibacterial and larvicidal activities. Journal of Nanostructure in Chemistry. 2015; 5: 295-303. doi: 10.1007/s40097-015-0161-2.

17) Poor MHS, Khatami M, Azizi H, Abazari Y. Cytotoxic activity of biosynthesized Ag Nanoparticles by Plantago major towards a human breast cancer cell line. Rendiconti Lincei. 2017; 28: 693-9. doi: 10.1007/s12210-017-0641-z.

18) Hamedi S, Shojaosadati SA, Shokrollahzadeh S, Hashemi-Najafabadi S. Extracellular biosynthesis of silver nanoparticles using a novel and non-pathogenic fungus, Neurospora intermedia: controlled synthesis and antibacterial activity. World J Microbiol Biotechnol. 2014; 30(2): 693-704. doi: 10.1007/s11274-013-1417y. PMID: 24068530.

19) Khatami M, Alijani H, Sharifi I, Sharifi F, Pourseyedi S, Kharazi S, et al. Leishmanicidal Activity of Biogenic Fe3O4 Nanoparticles. Sci Pharm. 2017; 85(4). doi: 10.3390/scipharm85040036. PMID: 29156612, PMCID: PMC5748533.

20) Sharifi F, Sharififar F, Sharifii, Alijani H, Khatami M. Cytotoxicity, leishmanicidal, and antioxidant activity of biosynthesized zinc sulfide nanoparticles using Phoenix dactylifera. IET Nanobiotechnology. 2017. doi: 10.1049/iet-nbt.2017.0204.

21) Mortazavi M, Khatami M, Sharifi I, Heli H, Kaykavousi K, Sobhani Poor MH, et al. Bacterial Biosynthesis of Gold Nanoparticles Using Salmonella enterica subsp. enterica serovar Typhi Isolated from Blood and Stool Specimens of Patients. Journal of Cluster Science. 2017; 28(5): 2997-3007. doi: 10.1007/s10876-0171267-0.

22) Benn T, Westerhoff $P$. Nanoparticle silver released into water from commercially available sock fabrics. Environ Sci Technol. 2008; 42(11): 4133-9. doi: 10.1021/es7032718. PMID: 18589977.

23) Khatami M, Heli H, Mohammadzadeh Jahani P, Azizi H, Lima Nobre MA. Copper/copper oxide nanoparticles synthesis using Stachys lavandulifolia and its antibacterial activity. IET Nanobiotechnology: Institution of Engineering and Technology. 2017; 11(6): 709-13. doi: 10.1049/iet-nbt.2016.0189.

24) Sedighi A, Montazer M, Samadi N. Synthesis of nano Cu2O on cotton: morphological, physical, biological and optical sensing characterizations. Carbohydr Polym. 2014: 110: 489-98. doi: 10.1016/j.carbpol.2014.04.030. PMID: 24906783.

25) Lim J, Yeap SP, Che HX, Low SC. Characterization of magnetic nanoparticle by dynamic light scattering. Nanoscale Res Lett. 2013: 8: 381. doi: 10.1186/1556-276X-8-381. PMID: 24011350, PMCID: PMC3846652.

26) Wang R, Yang W, Song Y, Shen X, Wang J, Zhong X, et al. A General Strategy for Nanohybrids Synthesis via Coupled Competitive Reactions Controlled in a Hybrid Process. Sci Rep. 2015; 5: 9189. doi: 10.1038/srep09189. PMID: 25818342, PMCID: PMC4377631.

27) Mahmoudi Moghaddam H, Beitollahi H, Tajik S, Jahani Sh, Khabazzadeh H, Alizadeh R. Voltammetric determination of droxidopa in the presence of carbidopa using a nanostructured base electrochemical sensor. Russian Journal of Electrochemistry. 2017; 53(5): 452-60. doi: 10.1134/S1023193517050123.

28) Beitollai H, Garkani Nejad F, Tajik S, Jahani Sh, Biparva P. Voltammetric determination of amitriptyline based on graphite screen printed electrode modified with a Copper Oxide nanoparticles. International Journal of Nano Dimension. 2017; 8(3): 197-205.

29) Jahani Sh, Beitollai H. Selective Detection of Dopamine in the Presence of Uric Acid Using NiO Nanoparticles Decorated on Graphene Nanosheets Modified Screen-printed Electrodes. Electroanalysis. 2016; 28(9): 2022-8. doi: 10.1002/elan.201501136. 
30) Beitollai H, Tajik S, Jahani Sh. Electrocatalytic Determination of Hydrazine and Phenol Using a Carbon Paste Electrode Modified with Ionic Liquids and Magnetic Core-shell Fe3O4@SiO2/MWCNT Nanocomposite. Electroanalysis. 2016; 28(5): 1093-9. doi: 10.1002/elan.201501020.

31) Khorasani-motlagh M, Noroozifar M, Jahani S. Preparation and Characterization of Nano-Sized Magnetic Particles LaCoO3 by Ultrasonic-Assisted Coprecipitation Method. Synthesis and Reactivity in Inorganic, Metal-Organic, and Nano-Metal Chemistry. 2015; 45(10): 1591-5. doi: 10.1080/15533174.2015.1031010.

32) Bankara A, Joshia B, Kumara AR, Zinjardea S. Banana peel extract mediated novel route for the synthesis of silver nanoparticles. Colloids and Surfaces A: Physicochem Eng Aspects. 2010; 368(1-3): 58-63. doi: 10.1016/j.colsurfa.2010.07.024.

33) Ingle A, Rai M, Gade A, Bawaskar M. Fusarium solani: a novel biological agent for the extracellular synthesis of silver nanoparticles. Nanoparticles Research. 2009; 11(8): 2079-85. doi: 10.1007/s11051-0089573-y.

34) Khadri H, Alzohairy M, Janardhan A, Kumar AP, Narasimha G. Green Synthesis of Silver Nanoparticles with High Fungicidal Activity from Olive Seed Extract. Advances in Nanoparticles. 2013; 2(3): 241 -6. doi: 10.4236/anp.2013.23034.

35) Kuppusamy P, Ichwan SJ, Parine NR. Intracellular biosynthesis of Au and Ag nanoparticles using ethanolic extract of Brassica oleracea L and studies on their physicochemical and biological properties. J Environ Sc. 2015; 29: 151-7. doi: 10.1016/j.jes.2014.06.050.

36) Awwad AM, Salem NM, Abdeen AO. Green synthesis of silver nanoparticles using carob leaf extract and its antibacterial activity. Awwad et al International Journal of Industrial Chemistry. 2013; 4: 1-6. doi: 10.1186/2228-5547-4-29.

37) Lateef A, Ojo SA, Azeez MA, Asafa TB, Yekeen TA, Akinboro A, et al. Cobweb as novel biomaterial for the green and eco-friendly synthesis of silver nanoparticles. Applied Nanoscience. 2015; 6(6): 1-12. doi: 10.1007/s13204-015-0492-9.

38) Jaganathan A, Murugan K, Panneerselvam C, Madhiyazhagan P, Dinesh D, Vadivalagan C, et al. Earthworm-mediated synthesis of silver nanoparticles: A potent tool against hepatocellular carcinoma, Plasmodium falciparum parasites and malaria mosquitoes. Parasitol Int. 2016; 65(3): 276-84. doi: 10.1016/j.parint.2016.02.003. PMID: 26873539.

39) Khatami M, Pourseyedi S. Phoenix dactylifera (date palm) pit aqueous extract mediated novel route for synthesis high stable AgNPs with high antifungal and antibacterial activity. IET Nanobiotechnol. 2015; 9(4): 184-90. doi: 10.1049/iet-nbt.2014.0052. PMID: 26224347.

40) Mirzajani F, Ghassempour A, Aliahmadi A, Esmaeili MA. Antibacterial effect of silver nanoparticles on Staphylococcus aureus. Res Microbiol. 2011; 162(5): 542-9. doi: 10.1016/j.resmic.2011.04.009. PMID: 21530652.

41) Wady AF, Machado AL, Foggi CC, Zamperini CA, Zucolotto V, Moffa EB, et al. Effect of a Silver Nanoparticles Solution on Staphylococcus aureus and Candida spp. Journal of Nanomaterials. 2014; 2014 : 7. doi: 10.1155/2014/545279.

42) Khameneh B, Zarei H, Fazly Bazzaz BS. The effect of silver nanoparticles on Staphylococcus epidermidis biofilm biomass and cell viability. Nanomedicine Journal. 2014; 1(5): 302-7. doi: 10.7508/nmj.2015.05.003. 